\title{
PREPARATION OF APPLE SPIRIT BY CERAMIC PERVAPORATION MEMBRANE
}

\author{
M.A. MolnÁR*, E. MÁRKI and Gy. VAtAi \\ Department of Food Engineering, Faculty of Food Science, Szent István University, H-1118 Budapest, Ménesi út \\ 44. Hungary
}

(Received: 5 March 2016; accepted: 15 July 2016)

This study was based on the production of an alcoholic beverage from apple using laboratory pervaporation equipment. Hungarian fruit brandy is called pálinka, which can be made by pot distiller or multistage distiller made of copper. In case of traditional pot still distillation the final product is gained from two separate distillations. Pervaporation is an energy efficient membrane process for separating liquid mixtures. Application of pervaporation to separate the product of the initial distillation leads to lower energy consumption than using double-distillation process. The aim of our work was to develop an alternative technology for the production of pálinka that integrates distillation and pervaporation

Keywords: pervaporation, apple spirit, distillation, pálinka

The traditional alcoholic beverage of Hungary is called pálinka. The production of this Hungarian speciality is regulated by the European Union. Pálinka is a fruit brandy that is made exclusively from fruit grown in Hungary. The fermentation of fruit, distillation, and bottling are also done in Hungary. Beside Hungary, the name "pálinka" can only be used by four Austrian provinces (Burgenland, Lower Austria, Styria, and Vienna), for a special distillate prepared from apricot. Pálinka can be prepared by two methods of distillation. In case of traditional pot still distillation, the mash is boiled to obtain the alcohol and other volatile components through distillation. The alcoholic liquid obtained is refined in a separate phase. Using column distillation apparatus, boiling and refining proceed at the same time in a single process called rectification (HARCSA et al., 2014). The major disadvantage of doubledistillation and rectification process is the high operating temperature, which leads to high energy consumption.

Pervaporation is a membrane technique for the separation of liquid mixture by selective transport through a non-porous membrane (HuANG, 1991; SoNG et al., 2002). During the method called "vacuum-pervaporation", low pressure is kept at the permeate side with vacuum, and during the method called "sweeping-gas pervaporation", carrier gas is circulated that delivers the permeate away. The liquid feed becomes vapour passing through the membrane. Permeate can be condensed by a cold surface, gaining a permeate of liquid phase (Song \& Lee, 2005; Pereira el al., 2006). The application of pervaporation in food industry has been investigated by several researchers for aroma compounds recovery or concentration in fruit juices (ÁLVAREZ et al., 2000; LIPNIZKI et al., 2002) and dealcoholisation of wine or beer (TAKÁCS et al., 2007). Though the capital cost of pervaporation process can be higher than distillation, pervaporation has many advantages, such as high selectivity, low energy

\footnotetext{
* To whom correspondence should be addressed. Phone: +36 1482 6113; e-mail: molnar.a.mate@gmail.com
} 
consumption, and minimum loss of aroma compounds (TAN et al., 2005; IsCI et al., 2006; YANG et al., 2006).

The aroma of fruit beverages consists of a large number of volatile organic compounds at ppm concentrations (RAIsI et al., 2008). The use of organophilic pervaporation membrane to recover aroma compounds from aqueous model solutions has been successfully demonstrated for alcohols, lactones, esters, aldehydes, ketones, sulphur compounds, and hydrocarbons (BAUDOT et al., 1999; TAN et al., 2005). The separation is not based on relative volatilities, as in the case of distillation, but rather on the relative rates of permeation through the membrane (GonZÁLEZ-RodRíGUEZ et al., 2003). Combining pervaporation and distillation could be a promising hybrid process for the substitution of double-distillation technique.

The aims of our experiments were to examine applicability of pervaporation in reference to the preparation of apple spirit and to compare the products of traditional distillation and pervaporation processes.

\section{Materials and methods}

\subsection{Materials}

In our study, an alcoholic beverage made by pervaporation was compared to a double-distilled apple pálinka prepared from the same raw material. Fermentation and distillation processes were carried out at the Department of Brewing and Distillation, Szent István University. The double-distilled spirit was produced in pot still by redistilling the product of the first distillation. The pervaporated apple spirit was prepared from the same initial distilled spirit using laboratory pervaporation equipment. Pervaporation process was performed at the Department of Food Engineering, Szent István University, Hungary.

\subsection{Apparatus}

The pervaporation system is shown in Figure 1. The thermostated feed was circulated between the feed tank and the module by a circulation pump. The separation of the first distillation was operated by an organophilic ceramic tube pervaporation membrane using vacuum-pervaporation method. The commercial membrane (Pervatech BV) with PDMS active layer has an outer diameter of $10 \mathrm{~mm}$, an inner diameter of $7 \mathrm{~mm}$, and a length of 50 $\mathrm{cm}$. The effective membrane area is about $0.011 \mathrm{~m}^{2}$. In the experiment, the feed temperature was maintained at $50{ }^{\circ} \mathrm{C}$ and the feed flow-rate was kept at $4001 \mathrm{~h}^{-1}$. The pressure on the permeate side was 20 mbar during the separation process. Permeate is collected in traps, which at laboratory scale are normally cooled by using liquid nitrogen $\left(-196{ }^{\circ} \mathrm{C}\right)$. All samples (permeate of pervaporation process, the first and second distillates) were analysed by gas chromatograph coupled to a mass spectrometer at Bálint Analytics. The major volatile compounds, beside ethanol, identified and quantified were methanol, 1-propanol, 1-butanol, isobutanol, 1-hexanol, ethyl acetate, ethyl hexanoate, ethyl octanoate, ethyl decanoate, and acetaldehyde. 


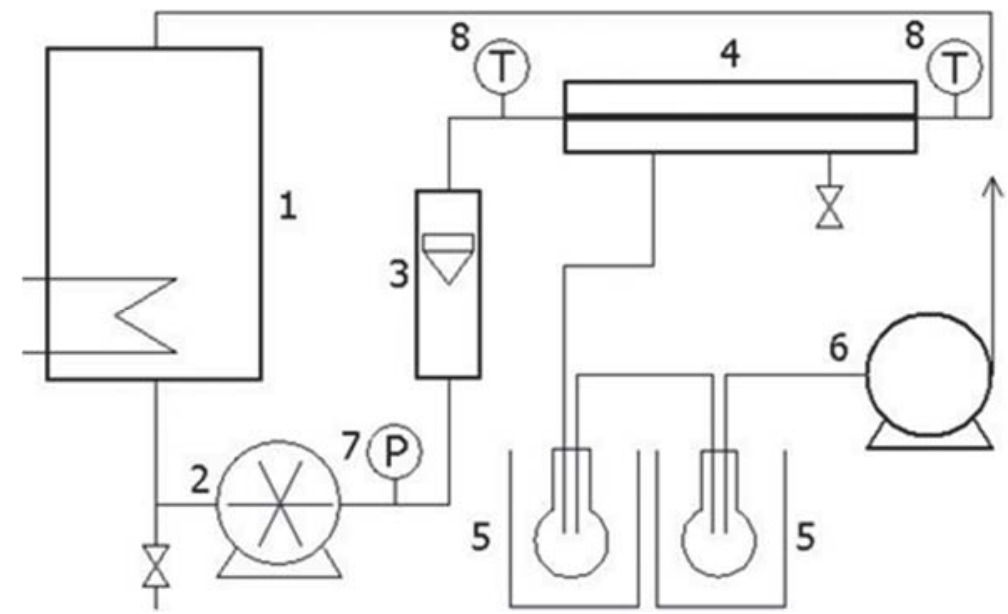

Fig. 1. Laboratory pervaporation equipment: (1) feed tank; (2) circulation pump; (3) flowmeter; (4) pervaporation membrane; (5) cold traps; (6) vacuum pump; (7) manometer; (8) thermometers

\subsection{Separation efficiency}

The characteristics of pervaporation can be described by factors like permeate flux and separation factor. The permeate flux was calculated by measuring the weight of the liquid collected in cold traps during a certain time through the membrane surface as follows:

$$
J_{p}=\frac{m_{p}}{\mathrm{~A} \cdot t}
$$

where $\mathrm{J}_{\mathrm{p}}$ is the permeate flux $\left(\mathrm{kg} \mathrm{m}^{-2} \mathrm{~h}^{-1}\right), \mathrm{m}_{\mathrm{p}}$ is the weight of permeate $(\mathrm{kg})$, A is the membrane surface $\left(\mathrm{m}^{2}\right)$, and $\mathrm{t}$ is the pervaporation time $(\mathrm{h})$. The separation factor describes the permeate concentration as a function of feed concentration:

$$
\alpha=\frac{\mathrm{C}^{\prime}(1-\mathrm{C})}{\mathrm{C}\left(1-\mathrm{C}^{\prime}\right)}
$$

where $\alpha$ is the separation factor $(-), \mathrm{C}^{\prime}$ and $\mathrm{C}$ are the concentrations of the aroma compound at permeate and feed side, respectively (m/m, \%) (CATARINO et al., 2009).

\section{Results and discussion}

The ethanol content of distilled and membrane separated spirits are shown in Table 1. The doubled-distilled apple pálinka, consisting of only the middle distillate, had an ethanol content of $79.3 \%(\mathrm{v} / \mathrm{v})$. The separation of the first distillate by pervaporation membrane leads to an ethanol content of $49.9 \%(\mathrm{v} / \mathrm{v})$. The alcohol content of pálinka must be between in 37.5 and 86 percent. In case of commercially available pálinka, the alcohol content must not exceed 55 percent. Dilution of the pot still distillate is necessary to achieve the required alcohol level. 
Table 1. Ethanol concentration of permeate, first and second distillates

\begin{tabular}{lccc}
\hline Spirits & Initial distillate & Pot still distillate & Permeate \\
\hline Ethanol concentration $(\% \mathrm{~V} / \mathrm{V})$ & 21.7 & 79.3 & 49.9 \\
\hline
\end{tabular}

Table 2 reports the fluxes and separation factors of the main volatile aroma compounds of the pervaporated apple spirit. Methanol, isobutanol, acetaldehyde, and ethyl acetate had the highest concentrations in the first distillate. Analysing the composition of permeate, it can be observed that higher concentration of the organic compound in the feed leads to higher permeate flux. From the pervaporation results in Table 2, it can be seen that esters had the highest separation factors, and the pervaporation membrane was not able to separate efficiently methanol from the initial distillate.

Table 2. Flux and separation factor of the investigated components

\begin{tabular}{lcc}
\hline Components & Flux, $\mathrm{g} \mathrm{m}^{-2} \mathrm{~h}^{-1}$ & Separation factor \\
\hline Methanol & 4.854 & 1.65 \\
1-Propanol & 0.518 & 5.76 \\
Isobutanol & 2.619 & 9.70 \\
1-Butanol & 0.817 & 7.23 \\
1-Hexanol & 0.580 & 23.94 \\
Ethyl acetate & 3.093 & 43.73 \\
Ethyl hexanoate & 0.059 & 210.05 \\
Ethyl octanoate & 0.065 & 115.26 \\
Ethyl decanoate & 0.005 & 16.80 \\
Acetaldehyde & 3.744 & 6.54 \\
\hline
\end{tabular}

During preparation of pálinka, the pre-distillate contains the most volatile compounds such as methanol, acetaldehyde, and ethyl acetate. Methanol is similar to ethanol in taste and smell, however it is toxic and potentially dangerous if present in high concentration. The maximum allowed methanol content of fruit spirit (second distillate and permeate) is 1000 grams per hectolitre of pure alcohol. The product of the first phase of distillation has low alcohol content and is unsuitable for human consumption. The methanol concentration (Fig. 2) of all investigated alcoholic samples did not exceed the permitted level, furthermore, the methanol concentration of the permeate is lower than the methanol concentration of real apple pálinka. From the results it can be concluded that the applied PDMS membrane has very low methanol selectivity. Regarding the analysis of methanol concentration we can say that pervaporation appears to be a promising technique to refine the first distillate. 


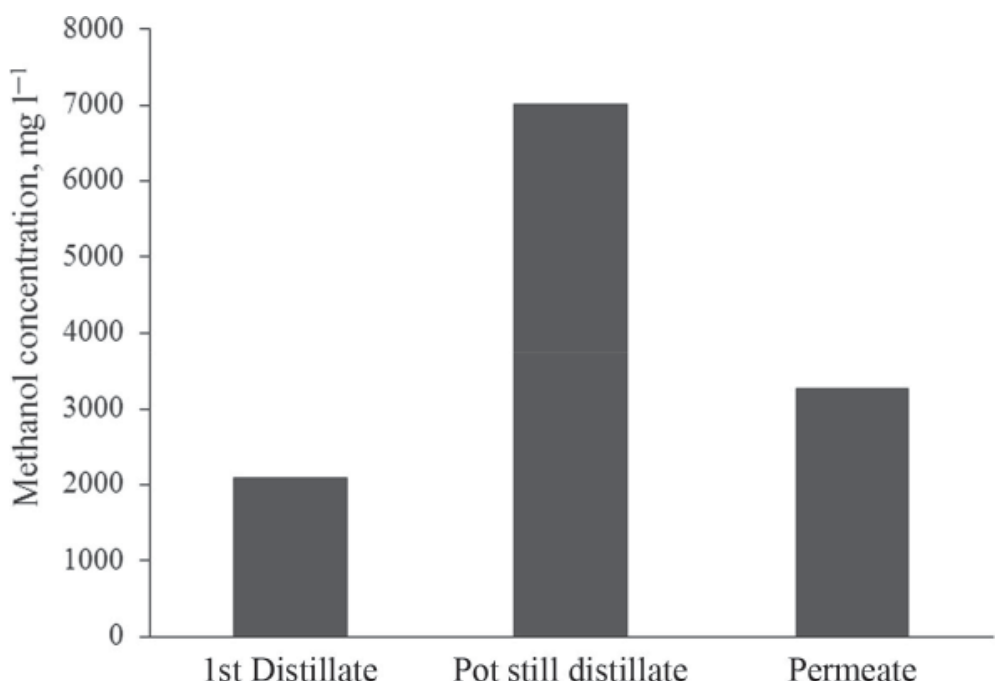

Fig. 2. Concentration of methanol in the distilled and pervaporated spirits

Fusel alcohols are defined as those alcohols that are larger than ethanol, and make up the largest group of aroma compounds in alcoholic beverages. Higher alcohols are created as a by-product of yeast fermentation and are important flavour compounds. Figure 3 shows the amount of higher alcohols, such as 1-propanol, isobutanol, 1-butanol, and 1-hexanol. In case of pot still distillation, these components are found in higher concentrations in the final fraction because of their higher boiling point than ethanol. Excessive concentration of fusel alcohols can result in a strong, pungent smell and taste. The enrichment of these alcohols by pervaporation has a negative influence on the aroma of the final spirit.

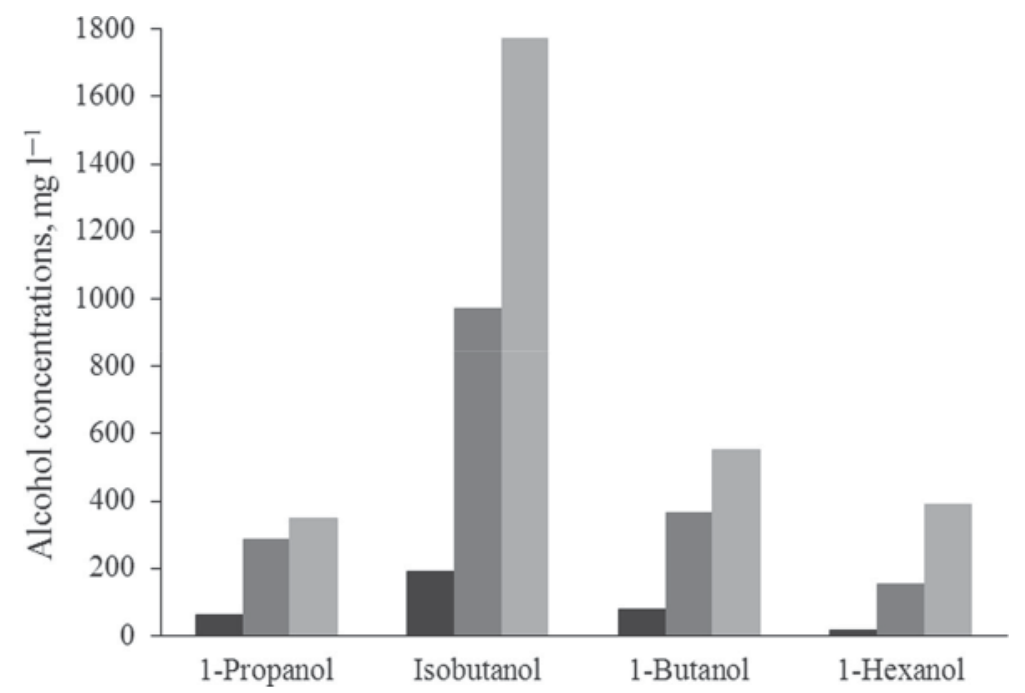

Fig. 3. Concentrations of other alcohols in the distilled and pervaporated spirits.

1st distillate; : pot still distillate; : permeate other alcohols: 1-propanol, isobutanol, 1-butanol, 1-hexanol 
Acetaldehyde and ethyl acetate are present in higher concentrations in the first fraction during batch distillation. It can be seen in Figure 4 that concentrations of both compounds are much higher in pervaporated spirit than in real apple pálinka. Acetaldehyde is an undesirable substance in spirits because of its unpleasant flavour. High level of ethyl acetate in pálinka causes a smell like nail polish remover. Esters are formed during the distillation and storage of the spirits and generally add positive tastes and odours to the distilled fruit spirits. Concentrations of the other esters (Fig. 5) are also higher in permeate than double-distilled spirit, leading to more intensive fruit flavour.

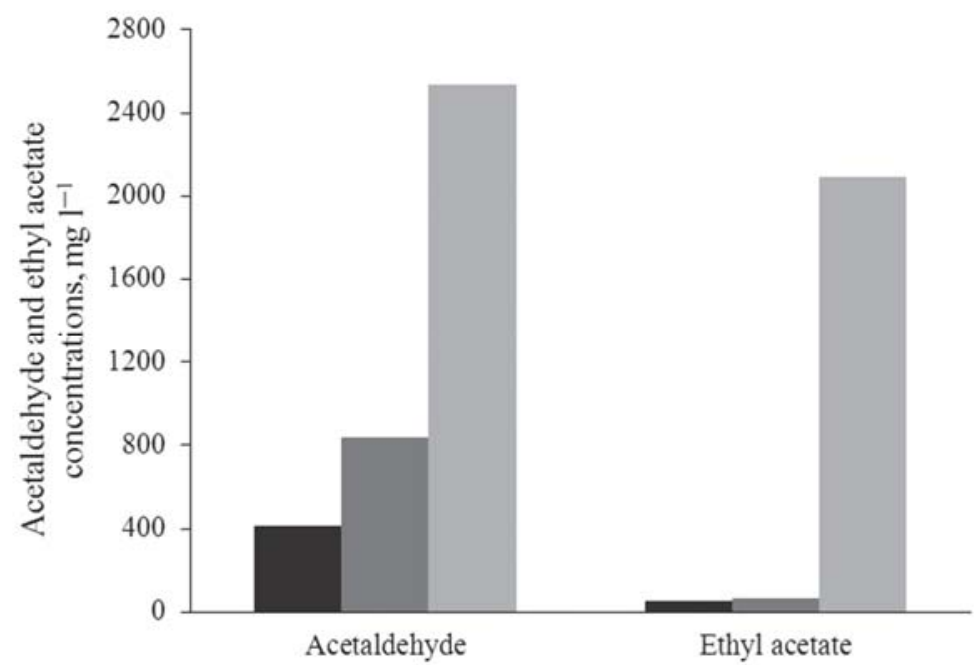

Fig. 4. Concentrations of acetaldehyde and ethyl acetate in the distilled and pervaporated spirits $\square$ : 1st distillate; $\square$ : pot still distillate; $;$ : permeate

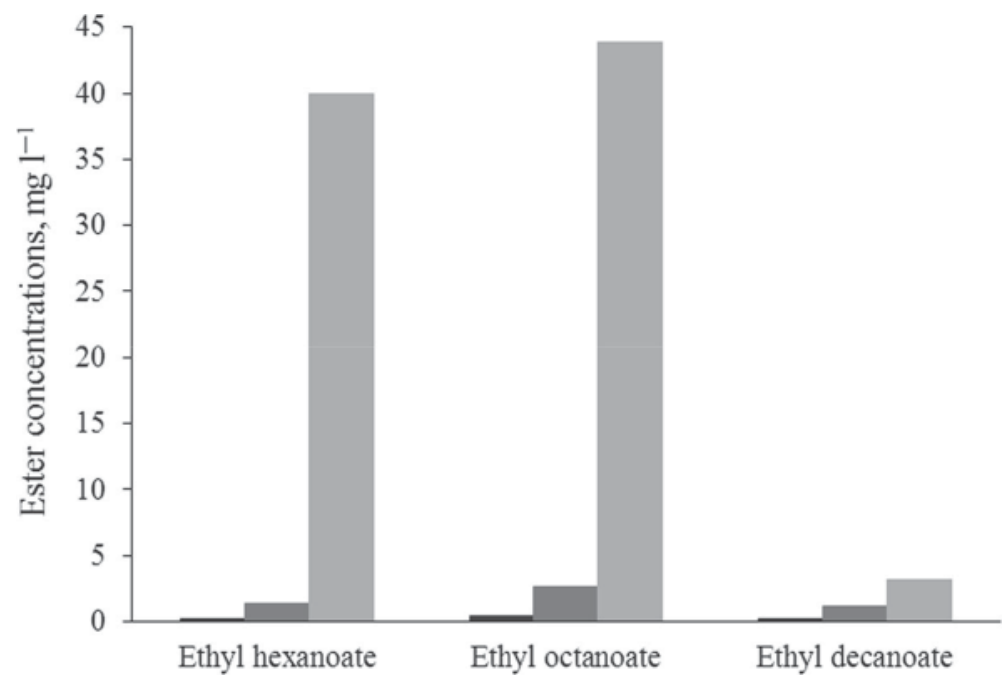

Fig. 5. Concentrations of other esters in the distilled and pervaporated spirits

1st distillate; : pot still distillate; : permeate; other esters: ethyl hexanoate, ethyl octanoate, ethyl decanoate 


\section{Conclusions}

As a conclusion it can be stated that the applied membrane is suitable for the separation of ethanol and other volatile components from the first distillate. On the other hand, pervaporation is not capable of refining the initial distillate, which leads to unpleasant taste and odour in permeate. The separation by pervaporation is not based on relative volatilities, as in the case of distillation, but rather on the relative rates of permeation through the membrane. Using another pervaporation membrane with lower selectivity of harmful volatile components is needed to produce alcoholic beverage with a pleasure fruit flavour and smell.

The authors would like to acknowledge the financial support of the Hungarian National Science Foundation (OTKA CK-81011) and the Hungarian Research Institute of Organic Agriculture (ÖMKI).

\section{References}

Álvarez, S., Riera, F.A., Álvarez, R., Coca, J., Cuperus, F.P., Th Bouwer, S., Boswinkel, G., van Gemert, R.W., Veldsink, J.W., Giorno, L., Donato, L., Todisco, S., Drioli, E., Olsson, J., TrägÅrdh, G., Gaeta, S.N. \& PANYOR, L. (2000): A new integrated membrane process for producing clarified apple juice and apple juice aroma concentrate. J. Food Eng., 46, 109-125.

Baudot, A., Souchon, I. \& Marin, M. (1999): Total permeate pressure influence on the selectivity of the pervaporation of aroma compounds. J. Membrane Sci., 158, 167-185.

Catarino, M., Ferreira, A. \& Mendes, A. (2009): Study and optimization of aroma recovery from beer by pervaporation. J. Membrane Sci., 341, 51-59.

GonzÁlez-Rodríguez, J., Pérez-Juan, P. \& Luque de Castro, M.D. (2003): Determination of ethanol in beverages by flow injection, pervaporation and density measurements. Talanta, 59, 691-696.

Harcsa, I.M., NÁBrÁd, A. \& TAR, I. (2014): Hungarian spirits pálinka as a "Hungaricum" I., Applied Studies in Agribusiness and Commerce APSTRACT, 8(2-3), 133-141.

HuAng, R.Y.M. (1991): Pervaporation membrane separation processes. Elsevier, Amsterdam, 549 pages.

Isci, A., SAhin, S. \& Sumnu, G. (2006): Recovery of strawberry aroma compounds by pervaporation. J. Food Eng., 75, 36-42.

LipNizki, F., Olsson, J. \& TrÄGÅRdh, G. (2002): Scale-up of pervaporation for the recovery of natural aroma compounds in the food industry, Part 2: Optimisation and integration. J. Food Eng., 54, 197-205.

Pereira, C.C., Riberio Jr., C.P., Nobrega, R. \& Borges, C.P. (2006): Pervaporative recovery of volatile aroma compounds from fruit juices. J. Membrane Sci., 274, 1-23.

Raisi, A., Aroujalian, A. \& Kaghazchi, T. (2008): Multicomponent pervaporation process for volatile aroma compounds recovery from pomegranate juice. J. Membrane Sci., 322, 339-348.

Song, K.M., Hong, Y.K., Yu, J. \& Hong, W.H. (2002): Influence of temperature drop by phase transition on pervaporation processes in vapor phase feed. Korean J. Chem. Eng., 19, 209-295.

Song, K-H. \& LeE, K-R. (2005): Pervaporation of flavors with hydrophobic membrane. Korean J. Chem. Eng., 22, 735-739.

TAKÁcs, L., Vatai, Gy. \& KorÁny, K. (2007): Production of alcohol free wine by pervaporation. J. Food Eng., 78, $118-125$.

TAN, S., Li, L., XiAo, Z., Wu, Y. \& Zhang, Z. (2005): Pervaporation of alcoholic beverages - the coupling effects between ethanol and aroma compounds. J. Membrane Sci., 246(1-2), 129-136.

Yang, J., Yoshioka, T., Tsuru, T. \& Asaeda, M. (2006): Pervaporation characteristics of aqueous-organic solutions with microporous $\mathrm{SiO}_{2}-\mathrm{ZrO}_{2}$ membranes: Experimental study on separation mechanism. J. Membrane Sci., 284, 205-213. 